\title{
Pontos divergentes da Educação Física em Escolas Públicas e Privadas: a visão de professores do Ensino Superior
}

\section{Divergent point of Physical Education in Public and Private Schools: a vision for university teachers}

\author{
${ }^{1}$ Cláudio Delunardo Severino claudiodelunardo@gmail.com \\ 2 Lidiana Gomes Adriano
}

\footnotetext{
1 Mestre, docente do Curso de Educação Física do Centro Universitário de Volta Redonda - UniFOA.

2 Discente do Curso de Educação Física do Centro Universitário de Volta Redonda - UniFOA.
}

\section{RESUMO}

A presente pesquisa objetiva compreender os pontos divergentes existentes no fenômeno da Educação Física Escolar em instituições públicas e privadas, a partir da visão dos professores que atuam, concomitantemente, em instituições de ensino superior da região Sul Fluminense e na Educação Básica. Para tal, foi realizada uma pesquisa qualitativa, com o foco de descrever e interpretar os significados e experiências dos indivíduos com precisão, por intermédio de entrevista semiestruturada, com seis docentes. Ficou explícito, sob o olhar dos entrevistados, que existem distinções entre as instituições públicas e privadas, referentes à ação pedagógica, à parte infraestrutural e ao papel atribuído às referidas escolas.

\section{Palavras-chaves:}

Educação física escolar; ensino público; ensino privado; formação continuada.

\begin{abstract}
This research aims to understand the existing divergent in physical education phenomenon in public and private institutions, from teachers view that act concurrently in higher education institutions in the Southern Region Fluminense and Basic Education. For this purpose, a qualitative research was conducted with the focus to describe and interpret the meanings and experiences of individuals accurately, through semi-structured interviews with six teachers. Was explicit, from the perspective of the respondents, there are distinctions between public and private institutions related to the pedagogical action, the infrastructural part and the role assigned to such schools.
\end{abstract}

\section{Keywords:}

Physical education; public education; private education; continuing education.

\section{Como você deve citar?}

SEVERINO, Cláudio Delunardo; ADRIANO, Lidiana Gomes. Pontos divergentes da Educação Física em Escolas Públicas e Privadas: a visão de professores do Ensino Superior. Cadernos UniFOA, Volta Redonda, n. 28, p. 91 105, ago. 2015. 


\section{INTRODUÇÃO}

A Educação Física Escolar é um conjunto de ações que propicia ao indivíduo a melhoria da aptidão e a aquisição de habilidades por meio da atividade física. Boyle et al. (2008) a compreendem como uma possibilidade de influência sobre a personalidade humana e, sendo assim, permitem aos jovens praticantes de atividades físicas uma integração entre o agir e o pensar, o que implica em um estilo ativo e benefícios para a qualidade de vida. Também se justifica o papel da Educação Física como auxiliar na aprendizagem de outras disciplinas escolares, caracterizando-a apenas como um complemento das outras matérias de ensino (BRACHT et al., 2007).

O quadro acima descrito desperta a discussão de que a Educação Física ainda não possui uma caracterização, no que tange ao seu papel na escola. E, em se tratando do ambiente escolar, Alarcão (2001) aponta uma inadequação diante das demandas sociais. Para isso, a autora propõe uma mudança paradigmática, baseando-se no diálogo com o pensamento e a reflexão sobre a vida existente por detrás de seus muros.

Para Candau (2002 apud RANGEL et al., 2008), a escola é percebida como uma instituição cultural, concebida para desenvolver uma relevante função social: transmitir cultura. A autora afirma que, em se tratando de um processo educativo, a sua inserção na cultura universal é primordial, o que leva o discente à possibilidade do discernimento a respeito do que a humanidade produziu no decorrer do tempo.

A presente pesquisa objetiva investigar as possíveis divergências entre as realidades da prática pedagógica da Educação Física, nas redes públicas e privadas de ensino, além da formação continuada e dos aspectos motivacionais vinculados à prática docente. Para isso, realizou-se uma revisão bibliográfica sobre as teorias acerca das características da Educação Física Escolar, além de uma análise sobre a perspectiva dos docentes de nível superior a respeito da Educação Física Escolar, tanto na rede privada, como na rede pública de ensino. Para a realização deste estudo, a metodologia empregrada foi uma pesquisa qualitativa por entender-se, a partir do conceito estabelecido por Gonçalves (2005), que tal método não possui a pretensão de enumerar ou medir categorias homogêneas. Ainda sobre a pesquisa qualitativa, Minayo (2010) observa que ela está associada à investigação das representativas das relações humanas, na qual as suas ações são influenciadas pelas emoções provenientes a partir das situações vivenciadas no cotidiano.

\section{REFERENCIAL TEÓRICO}

Antunes (2013), ao discutir questões vinculadas à escola pública, aponta o analfabetismo funcional como um aspecto negativo que se encontra muito elevado, com cerca de 32,5 milhões de brasileiros em tal condição, segundo o Índice Nacional de Analfabetismo Funcional (Inaf). Esses dados retratam a real condição da educação brasileira, em meio à desigualdade social, econômica, geográfica e cultural. Todavia, o mesmo autor indica que, em meio a tantos empecilhos que só fazem separar, ao invés de unificar a educação brasileira, existem exemplos de escolas de boa qualidade, e a qualidade não é referenciada apenas em escolas privadas ou em instituições educacionais que se localizam em municípios que desfrutam de uma boa economia, como o próprio autor relata.

Em muitos lugares as escolas abrigavam alunos filhos de pais de baixa renda e o acesso era longo e difícil. Apesar das adversidades, gestores e professores encontraram um caminho para um ensino consciente e uma aprendizagem significativa expressa não apenas nas avaliações a que foram submetidos, mas no poder de argumentação, empreendedorismo e inteligência revelado pelos alunos. (ANTUNES, 2013, p. 40). 
Assim sendo, constata-se que muitos mitos não são bem fundados, como que para se ter uma escola com bons resultados em avaliações como o ENEM, Prova ABC, Prova Brasil, entre outras, a mesma deverá melhorar sua infraestrutura ou deverá ser bem localizada.

De acordo com Silva (2008), percebe-se que, consensualmente, o sistema educacional brasileiro não vai bem. Nota-se também que nem sempre há uma análise sobre a função que a escola deve ter diante da sociedade. Por exemplo, teria a escola o papel de formar o cidadão, prepará-lo para uma profissão, adequá-lo à sociedade, despertar o seu pensamento crítico e interpretar as questões associadas ao mundo?

\begin{abstract}
A falta de "objetivação" favorece a que a escola fique à mercê de uma "aleatoriedade" que se tenta "controlar" via políticas públicas, que não alcançam suas finalidades por vários motivos. Destaca-se aqui, a falta de originalidade e o distanciamento das propostas, da realidade das escolas, incluindo cultura dos grupos, sua falta de continuidade devido aos aspectos sociopolíticos, que fazem parte do sistema brasileiro de gestão da Educação, seja na Federação, nos Estados e nos Municípios e, também aos "modismos" e dificuldades de aproximação dos estudos desenvolvidos academicamente e sua incorporação social (SILVA, 2002 apud SILVA, 2008, p. 2).
\end{abstract}

A autora complementa ao observar que o retrato da Educação Física em ambiente escolar não difere do quadro acima, já que essa disciplina encontra-se à mercê da escola na sua totalidade, mesmo que ela possua determinadas particularidades. Entretanto, a Educação Física, bem como as outras disciplinas presentes no currículo escolar, apresenta problemas com características pedagógicas, metodológicas e institucionais (SILVA, 2008).

Pimenta et al. (2013) visam responder o seguinte questionamento: Qual a "função" da escola em nosso país atualmente? Objetivando a resposta para essa indagação, os autores encontraram em Sacristán e Pérez Gómez (1998 apud PIMENTA et al., 2013) dois objetivos relativos à função social da escola: um seria a preparação dos alunos para o mercado de trabalho e o outro a formação plena do indivíduo para exercer sua cidadania e intervir na sociedade.

Em se tratando da Educação Física Escolar, Castellani Filho (2008) afirma que a disciplina é utilizada em algumas situações como um mecanismo a serviço de projetos que não apresentam uma característica voltada para um crescimento existencial de todos. Na verdade, muitas vezes, esses projetos (ou programas) são inseridos no espaço escolar e vinculados à Educação Física como um instrumento de manipulação que objetiva a manutenção do estado de alienação dos alunos que ficam distantes das transformações sociais.

Em relação e esses projetos e programas voltados para a área da Educação Física, Kanters et al. (2012) indicam que o ambiente escolar tem sido apontado como o principal espaço para a promoção de atividades físicas entre crianças e jovens. A principal razão associada a essa realidade é, segundo os mesmos autores, o fato de que existem escolas na maioria das comunidades. Contudo, talvez não seja essa a realidade encontrada em todas as escolas, principalmente a se considerar distinções entre os estabelecimentos de ensino públicos e privados. Para Demo (2007), as diferenças entre a escola pública e a particular são consideráveis.

A diferença maior possivelmente é que a escola particular é gerida pela iniciativa privada com base na pressão do mercado e dos pais dos alunos, do que segue que seu desempenho, mesmo não sendo aceitável, é mais elevado. Sugere-se também que a iniciativa mais promissora para superar este imbróglio seria apostar no professor, cuidando sistematicamente de sua formação permanente, dentro da premissa de que se o professor aprender bem, o aluno também o poderá fazer (DEMO, 2007, p. 181).

Mas será que o professor, em particular o de Educação Física, vem se propondo a cuidar permanentemente de sua formação? 
Para Antunes (2013), é de suma importância, para uma escola saudável e com uma excelente qualidade de ensino, ter professores preparados. Todavia, observa-se que professores com uma boa formação representam uma parcela pequena perante tamanha necessidade. Existem professores que apenas depositam conteúdos nos alunos, só enxergam uma forma de avaliar, muitas vezes, castigando o aluno. Uma das inúmeras soluções para evitar tal condição é a constante busca por uma capacitação mais completa, é o eterno debruçar-se diante de um livro e procurar estar permanentemente em formação.

Piaget (2008) observou que o professor não atingiu o conceito a que tem direito em relação aos valores intelectuais. Como exemplo, o mesmo autor colocou que um advogado, mesmo que não seja talentoso, deve o prestígio que possui a uma disciplina tanto respeitada, como respeitável. O professor que atua em âmbito escolar carece de um prestígio intelectual equivalente, fator mais notório ainda, quando se trata do professor de Educação Física.

Contudo, percebe-se a necessidade de enfatizar, apesar do conceito acima relacionado, a importância do professor no contexto social. Quanto ao papel do professor diante da sociedade, Libâneo (1990) afirma que o trabalho docente é parte integrante do processo educativo mais global, pelo qual seus membros são preparados para participação na vida social.

Sobre essa questão, o próprio Libâneo (1990, p. 16) completa:

\begin{abstract}
A educação - ou seja, a prática educativa - é um fenômeno social e universal, sendo uma atividade humana necessária à existência e funcionamento de todas as sociedades. Cada sociedade precisa cuidar da formação dos indivíduos, auxiliar no desenvolvimento de suas capacidades físicas e espirituais, prepará-los para a participação ativa e transformadora nas várias instâncias da vida social. Não há sociedade sem prática educativa não é apenas uma exigência da vida em sociedade, mas também o processo de prover os indivíduos dos conhecimentos e experiências culturais que os tornam aptos a atuar no meio social e transformá-lo em função de necessidades econômicas, sociais e políticas da coletividade.
\end{abstract}

Folle et al. (2008) apontam que a docência, em especial no magistério público, apresenta como característica básica: a seleção por intermédio de concursos públicos. Nesse caso,

\begin{abstract}
a efetivação em uma rede estadual de educação consente ainda a construção de uma carreira profissional, permitindo aos docentes projetar seus planos futuros e evitar o constante enfrentamento das incertezas do mercado de trabalho, o que poderá proporcionar, em muitos casos, uma percepção maior de satisfação com a sua qualidade de vida no trabalho (FOLLE et al., 2008, p. 215).
\end{abstract}

Não é difícil observar que a realidade dos docentes vinculados à escola privada não apresenta tais características, muito embora a remuneração desses profissionais, em muitos casos, seja maior em relação ao docente associado à escola pública, a incerteza do mercado de trabalho faz parte do cotidiano do professor de escolas privadas.

Além da questão acima, a qualidade da educação também é questionada, em se tratando de escolas públicas e privadas. Nasser (2011) observa que a propaganda que cerca a qualidade da escola privada inspira-se, principalmente, na medição da qualidade educacional, especificamente em se tratando da quantidade de discentes aprovados em vestibulares e dos resultados obtidos em avaliações promovidas pelo governo federal.

É comum, portanto, atualmente essa mesma lógica pautar as políticas formuladas para a escola pública. A difusão da escola privada como referência de educação de qualidade faz dela um modelo para questionar a educação pública oferecida. Assim, a educação privada passou também a pautar as demandas da educação pública, difundindo, muitas vezes com eficiência, determinadas concepções de educação (NASSER, 2011, p. 9).

Para Bracht et al. (2007), a relação do professor de Educação Física com a realidade escolar pública ou privada - transcende as situações comentadas anteriormente. Os autores reforçam o fato 
de que o docente de Educação Física enfrenta outro problema, principalmente em escolas públicas e instituições privadas afastadas dos grandes centros: a qualidade - e quantidade - dos materiais referentes às aulas, assim como a manutenção das quadras e outros equipamentos.

A existência de materiais, equipamentos e instalações adequadas, é importante e necessária para as aulas de Educação Física, sua ausência ou insuficiência pode comprometer o alcance do trabalho pedagógico. No entanto outros aspectos devem ser considerados, muito embora alguns professores justifiquem e condicionem as lacunas de seu trabalho à carência de tais estruturas (BRACHT et al., 2007, pp. 47-48).

Ressalta-se que, segundo os mesmos autores, o problema não deve ser vinculado unicamente ao espaço escolar, ou seja, sua existência ou não. Torna-se importante discutir também a dimensão pedagógica desses espaços, já que a sua inexistência pode ser considerada como um indicador da posição de menor importância da Educação Física na hierarquia dos saberes educacionais.

\section{METODOLOGIA}

Para a coleta de dados, utilizou-se como instrumento uma entrevista semiestruturada. As entrevistas foram realizadas individualmente, de acordo com as necessidades e possibilidades dos docentes envolvidos na pesquisa. A construção do instrumento baseou-se nas categorias construídas a partir da revisão bibliográfica (SANTOS, 2011).

Por se tratar de uma pesquisa qualitativa, Boyle et al. (2008) observam que o seu objetivo é referente à descrição e à interpretação dos significados e experiências de indivíduos com a maior precisão possível. Para a construção desta pesquisa, foram utilizados critérios e categorias para se verificar como uma opinião ou comportamento se manifesta.

Ainda sobre a pesquisa qualitativa, Agee (2009) também apresenta uma observação acerca da mesma, na qual se considera que nesse tipo de investigação há o envolvimento de questões que contemplam o "porquê" e o "como" das interações humanas. Para isso, buscam-se, segundo a autora, as opiniões dos sujeitos no sentido da compreensão das perspectivas deles em relação às mudanças sociais. Cruz e Palmeira (2009) complementam essa afirmação ao observarem que a pesquisa qualitativa busca a compreensão sobre a natureza geral de uma questão a partir da criação de espaços para interpretação.

\subsection{Participantes}

Os sujeitos da pesquisa consistiram em professores graduados em Licenciatura Plena em Educação Física e que lecionam no Ensino Superior, sendo que o número de docentes entrevistados foi seis $(n=6)$. Os critérios para a seleção dos sujeitos foram: efetivos dos quadros de docentes de instituições de ensino superior da região Sul Fluminense e que também façam parte do quadro de docentes das redes pública e privada dos municípios da referida região.

Ressalta-se que somente participaram da pesquisa os professores que cumpriram com toda a documentação necessária, de acordo com o Comitê de Pesquisas em Seres Humanos do Centro Universitário de Volta Redonda - UniFOA. O projeto foi submetido e aprovado pelo Parecer Consubstanciado $\mathrm{n}^{\circ}$ 413.493 e Certificado de Apresentação para Apreciação Ética nº 22133713.0.0000.5237. 


\subsection{Métodos de coleta de dados}

As entrevistas foram realizadas com os docentes com o intuito de investigar as possíveis divergências entre as realidades da prática pedagógica da Educação Física nas redes públicas e privadas de ensino, além da importância da formação continuada do professor de Educação Física e a sua motivação para o exercício das funções docentes. Na entrevista, foram aplicadas 4 (quatro) questões, sendo elas: a) Em sua opinião, como a disciplina (Educação Física) é vista na instituição em que atua?; b) Partindo do princípio de que nem sempre a Educação Física tem o reconhecimento de sua importância no ambiente escolar, como você identifica os aspectos motivacionais da prática docente, ou seja, em sua opinião, o que leva o professor a se motivar a ministrar aulas de Educação Física Escolar?; c) Considerando a importância do professor de Educação Física no contexto social, você considera importante a formação permanente do profissional? Caso a resposta seja afirmativa, qual seria essa importância?; d) Seja no campo metodológico, estrutural ou pedagógico, você considera que há diferenças entre a escola pública e a privada? Caso haja diferenças, quais seriam?

A construção do instrumento de coleta de dados baseou-se nas categorias empíricas construídas a partir da revisão bibliográfica relacionada aos processos metodológicos de avaliação. A partir da designação de algumas questões prioritárias que passaram por um processo de análise e seleção no qual algumas foram refeitas ou excluídas, as categorias organizadas foram: a Educação Física na escola, a motivação do docente, formação permanente e diferenças entre a escola pública e a privada.

A coleta de dados foi realizada por intermédio de entrevista registrada em áudio. Após esse procedimento, os dados obtidos foram criticados à procura de falhas sistemáticas no planejamento, aquisição e armazenamento de dados.

Foram registradas entrevistas áudio-gravadas com 4 professores do sexo masculino e 2 do sexo feminino, sendo que a duração média das entrevistas foi de 23 minutos. Após a realização das entrevistas, os dados coletados foram transcritos por intermédio de digitação para posterior análise. A considerar que o gravador oportuniza a coleta das respostas dadas pelos participantes sem que se perca qualquer dado, para a realização das entrevistas, o equipamento utilizado foi um aparelho digital Sony ICD-PX312F 2GB.

\subsection{Validação do instrumento}

Para a validação do instrumento, obedeceu-se a dois procedimentos. No primeiro momento, o instrumento foi validado qualitativamente por 2 professores com notório conhecimento sobre a área de estudo, que sugeriram e orientaram sobre algumas modificações, no sentido de tornar o guia de entrevista mais objetivo e coerente com o objetivo do estudo. Após esse procedimento e para testar a confiabilidade do instrumento, ele foi submetido a um teste-piloto, o qual foi aplicado a uma amostra de 2 professores com experiência em Educação Física Escolar. A seguir, foi solicitado aos professores que apresentassem informações e sugestões no que tange ao grau de compreensão das perguntas, tempo de aplicação da entrevista e acréscimo ou retirada de questões. Essa solicitação teve como principal objetivo a apuração da qualidade do instrumento, bem como a percepção de uma possível adequação do procedimento de coleta de dados.

\subsection{Métodos de tratamento de dados}

Após o procedimento de coleta de dados, faz-se necessário a soma e processamento das informações obtidas. Esse processo inicia-se a partir de uma análise crítica dos dados, estabelecimento 
de critérios de classificação e tratamento estatístico que possibilita uma observação detalhada das hipóteses elencadas.

Os dados colhidos nas entrevistas foram submetidos a uma análise de conteúdo pelo programa NVIVO 7, software, especificamente projetado para analisar os dados qualitativamente (Boyle et al., 2008), realizando-se, posteriormente, uma análise interpretativa dos resultados, com o intuito de se obter as porcentagens de ocorrência e os resultados de frequência.

\subsection{Análise dos dados}

Após a organização das entrevistas devidamente transcritas, realizou-se a etapa que consistiu na criação de categorias (códigos) e a análise das transcrições, com os recortes devidamente inseridos nas categorias criadas. A concepção de categorias, de acordo com Bardin (2011), oportuniza a compreensão dos significados das informações obtidas, colocando-as adequadamente em seus respectivos contextos.

Essas categorias apresentam, como componente principal, o objeto de estudo, o que, para Souza Junior et al. (2010), torna-se relevante na análise, em função da sua apresentação sobre o que se deseja investigar e como se expressarão. Salienta-se que as categorias foram estabelecidas de acordo com o objetivo do presente estudo (Figura 1).

Figura 1 - Modelo de identificação das categorias analíticas para conhecimento do objeto de estudo.

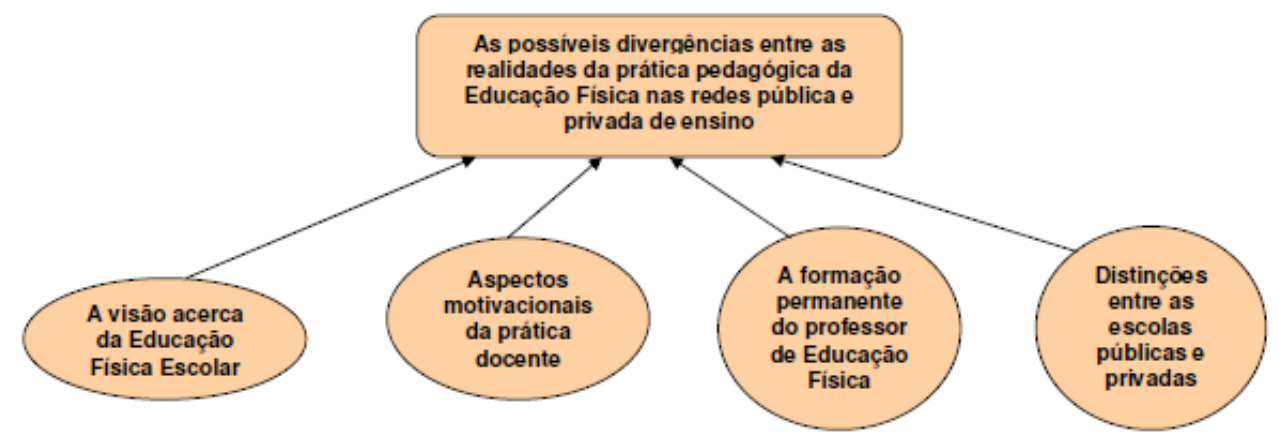

\section{RESULTADOS E DISCUSSÃO}

Dos docentes que participaram da entrevista, todos fazem parte do corpo docente de uma instituição de ensino superior; 4 atuam em escolas da rede pública da região Sul Fluminense e 2 dos docentes entrevistados, em escolas da rede privada.

Quanto à qualificação dos entrevistados, o número de professores mestres é superior ao número de especialistas, repetindo-se o resultado acima, sendo 4 e 2 , respectivamente. Porém, dentre os professores mestres, 2 encontram-se cursando o doutorado.

Logo após a caracterização dos participantes, parte-se para a apresentação das categorias, elencadas de acordo com as respostas obtidas na entrevista, representadas na tabela a seguir: 
Tabela 1 - Incidências das respostas apresentadas

\begin{tabular}{lll}
\hline $\begin{array}{l}\text { Possíveis divergências entre as realidades da prática pedagógica da Educação Física nas redes pública e } \\
\text { privada de ensino }\end{array}$ & Valorização Salarial (2) & Informalidade (4) \\
\hline O papel do professor (4) & Ambiente de trabalho (2) & Incentivo (1) \\
Interdisciplinaridade (2) & Estabilidade (1) & Transformações sociais (4) \\
Valorização (6) & Ideais (2) & Ações pedagógicas (3) \\
Fatores socioeconômicos (2) & Participação dos alunos (2) & Infraestrutura (5) \\
Identificação (3) & Família (1) & O papel da Educação Física (6) \\
Motivação intrínseca (4) & Formalidade (2) & Condições socioeconômicas (3) \\
Condições docentes (2) & & Papel social (2) \\
\hline
\end{tabular}

Em relação ao entendimento acerca da Educação Física Escolar dos entrevistados, 4 apontaram a importância do papel do professor, pois, segundo os mesmos, é por meio da conduta do professor que a disciplina terá visibilidade e reconhecimento dentro das instituições. Na atualidade, a disciplina ainda tem pouca significação social e pouco se vê mudanças de qualidade na prática pedagógica por parte dos docentes (SILVA, 2008). E ainda observaram, de forma pejorativa, como Antunes (2013), a existência de professores que praticam o depósito de conteúdos sobre os alunos.

Eu vejo que o papel que o professor tem dentro da escola é que dá a visibilidade, a validade pedagógica à disciplina $(\mathrm{P} 1)$.

Não basta eu chegar na escola e distribuir material para que os alunos se desenvolvam diante daquele material. Eu tenho que ter uma noção clássica da proposta curricular da escola ou da rede a qual a escola pertence (P5).

Já a interdisciplinaridade foi citada por apenas 2 docentes, que alegaram que a mesma faz com que a Educação Física possa ser vista pela sua validação pedagógica e não como apenas uma disciplina compensatória. Para Silva (2008), a Educação Física é tida como descartável por nossa sociedade extremamente ligada ao aspecto produtivo, fazendo com que a disciplina seja compreendida como secundária, já que a ludicidade que a envolve não se baseia em uma visão econômica.

Todos os participantes frisaram de alguma forma, a valorização. Não obstante, 2 professores suscitaram o fato de ela não ser valorizada no ambiente escolar em que atuam devido a dois fatores: a hierarquização das disciplinas e o descaso da Educação Física no Ensino Médio.

\footnotetext{
Existe uma hierarquia das disciplinas dentro da Educação Básica, como existe em muitos outros lugares. Então, você tem disciplinas do primeiro escalão, as disciplinas mais nobres, Química, Física, Matemática, Português, depois você umas disciplinas no meio do caminho, você tem Biologia, Geografia, Historia e depois você aquelas outras disciplinas que ficam mais abaixo nessa hierarquia que eu imagino que eu percebo que existe nas escolas, que é a Educação Física, Inglês, Artes, etc. (P4). (sic)
}

É porque na instituição que eu atuo, eu atuo no Ensino Médio e acredito que quanto mais próximo do último ano do Ensino Médio, mais a Educação Física é deixada de lado (P3).

Quanto ao primeiro fator, Silva (2008) aponta que a desvalorização de algumas disciplinas, por parte de uma comunidade, é decorrente do grau de importância que as pessoas dão às mesmas, partindo do ponto do quão são relevantes em suas vidas. Assim, há um "ranqueamento" das disciplinas 
de maior relevância, ditadas pela sociedade, e a realidade em que elas se encontram inseridas, além da desvalorização das outras disciplinas que fogem dessa realidade.

Em relação ao descaso da Educação Física no Ensino Médio, Silva e Maciel (2009) relatam que ocorre um distanciamento entre a proposta curricular e a realidade cultural dos alunos. Isso faz com que ocorra uma dificuldade, por parte dos professores, de se conectarem ao mundo de seus discentes, depauperando assim as relações pedagógicas e sociais.

Quatro docentes afirmaram que a Educação Física é valorizada e respeitada nas instituições em que atuam e que possuem um espaço para dialogar com as outras disciplinas, por meio de atividades interdisciplinares. Para eles, a disciplina faz parte, de maneira efetiva, dos projetos e ações pedagógicas das instituições, demonstrando assim a valorização, reconhecimento e respeito perante a Educação Física.

[...] lá ela é muito valorizada, todas as equipes de profissionais lá sabem que o colégio precisa da Educação Física, por que ela é um dos pilares... (P6). (sic)

É vista com muito respeito, até com um certo entendimento do que a gente se propõe a fazer, eu vejo isso. Até porque a gente participa da construção da proposta curricular, a gente participa das metas da escola, a gente participa dos conselhos de classe, a gente faz questão disso (P5).

Os fatores socioeconômicos foram abordados por 2 entrevistados. De um lado, a realidade de uma escola da periferia, com relatos de que a localização da instituição ocasiona dificuldade extramuros. Já do outro lado, a realidade de uma escola particular, observada pelo segundo docente, caracterizada pela preparação para o vestibular, com o foco nas universidades públicas. E isso, para Demo (2008), é pautado como sendo, possivelmente, a maior diferença entre a escola pública e a particular, pois a segunda é administrada por uma iniciativa privada e sofre uma forte pressão pelos pais dos alunos e do mercado. Para Silva (2008), é esse mercado que dita quais as competências profissionais devem ser trabalhadas junto aos discentes.

Em se tratando dos aspectos motivacionais da prática docente, são vistos como um fator de vital importância, na relação professor e aluno.

A motivação pode ser o principal fator a influenciar no comportamento de uma pessoa no processo ensino-
-aprendizagem, pois influi com muita propriedade, em todos os tipos de comportamentos, permitindo um maior
envolvimento ou uma simples participação em atividades que se relacionem com: aprendizagem, desempenho
e atenção. (GOUVEIA, 2007 apud FRANÇA et al, 2012, p.1).

Dos entrevistados, dentre outros aspectos motivacionais, citou-se a identificação. Dois docentes $(33,4 \%)$ suscitaram a relevância dos professores em se identificarem com a profissão, de gostar daquilo que se faz para que, posteriormente, ele não venha a ser um profissional frustrado, prejudicando assim a sua prática docente.

Primeiro, gostar do que ele faz. Eu sou apaixonada pela Educação Física, eu gosto do que faço (P1).

O segundo aspecto, relatado por 3 professores, foi a motivação intrínseca, que, para Woolfolk (2000 apud FRANÇA et al., 2012), trata-se de uma disposição natural do indivíduo em procurar e vencer desafios, de acordo com seus interesses particulares, como também prazer ou curiosidades. Dentro dessa visão, um professor afirmou estar bastante desmotivado, comparando-se com o começo de sua atuação docente. Já outro considerou que é muito importante o professor ter força de vontade em meio a esse cenário não favorável em que a Educação Física Escolar se encontra. 
Então, a motivação é algo que é interno. Você não tem como motivar o outro, você tem como criar situações facilitadoras pra essa motivação, mas é o aluno que vai se motivar e o professor precisa disso também (P1). (sic)

Eu diria que é a realização pessoa, é a missão que você tem que, que você acredita que tem e mesmo contra todos, você vai lá e cumpre (P3).(sic)

O outro aspecto, condições docentes, mencionado por 2 entrevistados, está ligado diretamente ao fator supramencionado. Um docente afirmou que as condições de trabalho influenciam na motivação do professor. Um dos entrevistados mostrou-se entristecido com a decisão de alguns colegas em optarem por deixarem a profissão devido à falta de valorização, condições essas que, para Witter (1992 apud França et al., 2012, p. 3), abrange as seguintes questões:

[...] a formação, ou falta de formação adequada, os baixos salários, a desvalorização social do professor, as condições materiais em que se vê compelido a trabalhar, a falta de um sistema adequado de reforços (ou recompensas) pelo empenho em concretizar um bom trabalho, a diversidade dos alunos, a falta de uma boa administração do tempo, planejamentos deficientes, a sobrecarga de trabalho (em número de alunos, de turmas e até de escolas que atua) [...].

Quanto à valorização salarial, 2 docentes declararam que o salário influencia na motivação, mas que a escolha da profissão foi independentemente desse fator. 0 mesmo percentual de professores afirmou que o bom ambiente de trabalho representa um aspecto motivacional, bem como a relação com a equipe diretiva, com outros professores e, sobretudo, com os alunos e com a própria comunidade escolar.

Apenas um professor participante revelou que a estabilidade é, para ele, um aspecto motivacional, pois falta pouco tempo para que ele possa se aposentar. Ressalta-se o fato de ele atuar na rede pública de ensino. Para Folle et al.(2008), a docência pública, por intermédio do concurso, permite que os professores não enfrentem as inseguranças do mercado de trabalho.

A respeito do aspecto ideais, 2 entrevistados comentaram que os seus representam o principal motivo para continuarem lecionando.

\footnotetext{
[...] ainda continuo pelos ideais que me formei, de estar ali dentro, você ainda tem aquela esperança de conseguir fazer alguma coisa, muito menos do que eu tinha antes, mas você ainda tem aquele ideal, aquela chama que ainda fica acesa ali (P2).(sic)
}

Eu acho que é o motivo pelo qual eu volto lá e mesmo contra todos, eu faço isso, é saber que eu posso contribuir e o que eu tenho pra contribuir é fundamental para a formação daquele adolescente, falando de Ensino Médio (P3).

O mesmo número de professores alegou que encontram motivação também na participação dos alunos, relatando que as experiências vividas com eles fortalecem o docente. Um dos entrevistados trouxe o fato de que, na instituição em que atua, a Educação Física não reprova, e que os alunos participam das aulas porque gostam, o que é a maior motivação para o professor.

Somente um professor trouxe como aspecto motivacional a influência da família, revelando que sempre foi muito estimulado, não só pela sua família, mas pelo meio, a exercer o magistério.

Quando o assunto é a formação permanente do professor de Educação Física, todos os docentes entrevistados consideram de suma importância o constante desenvolvimento profissional. De acordo com Antunes (2013), é muito importante para uma escola saudável e com uma excelente qualidade de ensino, ter professores preparados. Todavia, observa-se que professores com uma boa formação é uma parcela pequena perante tamanha necessidade. 
Essa formação permanente foi vista pelos entrevistados em dois campos: sendo o primeiro o da formalidade, citado por 2 docentes, que é representada por eles.

[...] nos cursos que a gente tem de pós- graduação lacto e stricto sensu [...](P1).

E essa atualização permanente, a gente pode entender de duas maneiras, uma coletiva e fomentada pela instituição que trabalha etc (P4).

E o segundo campo, a informalidade, sobre a qual três professores declararam que se encontra no cotidiano, quando o docente busca o conhecimento, lendo um livro ou participando de um evento acadêmico. Frisaram que o conhecimento é mutável e que, por isso, o professor deve estar em constante atualização em sua formação, pois o que é uma verdade hoje, amanhã poderá não ser mais. Contudo, um docente fez a seguinte crítica, em relação ao incentivo dado para que essa formação permanente de fato ocorra.

[...] eu tenho uma critica muito seria em relação a isso. Eu vejo que eles exigem muito do profissional, mas dão muito pouco. Então, por exemplo, essa formação permanente, essa constante possibilidade de você poder desenvolver cursos, de participar de cursos, isso é muito bonito em um discurso, mas não se aplica na prática. Então o que acontece: o profissional é que tem que fazer, porque o Estado não possibilita isso ao professor (P2).

Outro ponto muito abordado pelos docentes foram as transformações sociais. Segundo os professores, os conhecimentos vêm mudando com velocidade considerável. Esse fato torna essencial a atualização por parte do docente, pois ele não pode ensinar algo que não sabe.

A relação do aluno com a sociedade está cada vez mais mutante a cada momento. Não digo nem a cada geração, porque isso aí já era. Está assim no mesmo ano. Você vê uma turma lidar com uma coisa no inicio do ano e, em julho, já é outra coisa e, em novembro, aquilo que dava certo, já não dá mais e você tem que mudar de novo (P3).

Eu acredito nisto: ninguém pode parar no tempo. Na formação continuada é que você consegue vislumbrar o problema no tempo que você vive (P6).

Na última categoria, referente às distinções entre as escolas públicas e privadas, para se observar possíveis diferenças nos aspectos metodológico, pedagógico ou estrutural das mesmas, constatouse que três entrevistados citaram as ações pedagógicas. Dentre esses, apenas 1 alegou não acreditar que existem diferenças metodológicas e pedagógicas entre a escola pública e privada, partindo-se da premissa de uma escola de qualidade, com professores competentes, pois segundo o mesmo:

[...] tanto a parte metodológica quanto a pedagógica, ela não tem tanto diferencial, porque o que vale são as teorias da educação que estão por de trás de tudo isso [...] (P1)

Apontou-se um fato interessante, que o mesmo professor que ministra aulas na escola pública, muitas vezes também o faz na escola privada. E como ele pode ser bom em uma e ruim na outra? Um dos entrevistados complementa, citando alguns aspectos para que isso ocorra e dá o exemplo de que, na escola pública, o professor tem um espaço que ele pode se expor democraticamente e, na escola privada, existe um certo receio de fazer o mesmo, por medo de suas ideias não irem na mesma direção das que a escola incorpora.

Um dos entrevistados coloca que a escola particular consegue articular um projeto pedagógico para um grupo (de professores, alunos, equipe administrativa) que ela visualiza e consegue verificar, com fatos e dados, o procedimento ao longo dos anos. Entretanto, em se tratando da escola pública, o mesmo entrevistado diz: 
Na escola pública o que acontece, por mais que as pessoas queiram organizar um programa geral do ensino, traçar um projeto político pedagógico para escola, existem muitas diferenças entre um bairro e outro, existe muita diferença até entre duas escolas municipais que estão centralizadas no mesmo bairro (P6).

Sobre a infraestrutura, observou-se, praticamente, uma unanimidade quanto à existência de diferenças entre a escola pública e privada. Na escola pública ainda se observa uma precariedade em relação à infraestrutura e, na escola privada, até por uma questão de marketing, procura-se se equipar com excelência. Nilan (2003 apud Folle et al., 2008), à respeito dessa deficiência da escola pública, menciona que, enquanto servidores públicos, os docentes necessitam de melhores salários, infraestrutura e recursos pedagógicos de base. Já um dos entrevistados relata, a seguir, como que esse empecilho prejudica as escolas públicas, rotulando-a como dependente e frisando a importância de sua autonomia.

Na escola pública, vai esperar chegar o uniforme, vai esperar o governo federal mandar o livro e, na escola particular, não. Até o dia tal, todo mundo deverá ter esse livro. Então, eu acho que isso logicamente traz um resultado mais rápido $(\mathrm{P} 6)$.

Porém, não se vincula o fazer pedagógico unicamente à questão estrutural, citando o fato que muitos professores que trabalham na rede pública e não possuem um equipamento sofisticado conseguem dar excelentes aulas. Em contrapartida, existem docentes que atuam na rede privada, possuem um aparato de materiais e não conseguem desenvolver boas aulas.

Quando questionados em relação ao papel da Educação Física, observou-se a importância de se desenvolver, não somente o aspecto motor por intermédio da prática esportiva, mas que, inclusive, a disciplina pode vir a servir também como um caminho para a promoção de situações, para que o aluno compreenda a sociedade atual em que vive, possibilitando que atue sobre ela, para a sua formação quanto cidadão. Citou-se também o papel inclusivo da disciplina de trabalhar a diversidade e o respeito mútuo.

A respeito das condições socioeconômicas, três entrevistados alegaram observar, com clareza, diferenças quanto a essa questão, citando, por exemplo, que o público-alvo na instituição pública é completamente diferente de uma escola privada. Para Demo (2007), essa é, provavelmente, uma das grandes diferenças entre essas duas instituições, pois a instituição particular lida com uma grande influência do mercado. Sendo assim, uma é composta por uma classe mais favorecida financeiramente e a outra nem tanto, com realidades opostas.

Segundo um dos entrevistados, existem diferenças, pois há, em nosso país, uma classe que domina e uma que é dominada.

Portanto, eu considero que há uma diferença sim, mas uma diferença construída pela elite, pela classe dominante brasileira, no intuito de criar um entendimento entre aspas, de que a escola pública é obsoleta e a escola privada é a melhor opção (P5).

O mesmo ainda completou, relatando que, muitas vezes, essa sociedade dominada vê o crescimento de classe social atrelado ao poder aquisitivo, à capacidade de se consumir algo.

[...] se eu consigo comprar um celular, ah, então eu já pertenço à classe media, mesmo que eu não tenha um ensino de qualidade, que eu não tenha um clube de lazer, mesmo que eu não tenha plano de saúde, mesmo que eu não tenha transporte público de qualidade, mesmo que eu não tenha segurança, mas eu consigo comprar um celular em 30 vezes, ah, então eu já sou da classe média (P5).

Sobre o papel social, dois entrevistados expuseram que a escola pública apresenta qualidade, mas que a forma com que a escola particular e pública lidam com os alunos é distinta. Nesse caso, a pública presta um serviço social, função que a escola particular não possui, pois é mais focada para a 
transmissão de conhecimentos. Nela, o aluno que tem que se adaptar às suas diretrizes, diferente do que ocorre na instituição pública.

Como se a escola particular preparasse ele para ser aprovado e seguir e a escola pública se preparasse mais em preparar o aluno para pensar a vida. E aí quando se chega nesse confronto e esse confronto é feito através de conhecimento acumulado, o aluno da escola particular, na maioria das vezes, leva vantagem [...] (P4).(sic)

\section{CONSIDERAÇÕES FINAIS}

A presente pesquisa almejou investigar as possíveis divergências entre as realidades da prática pedagógica da Educação Física nas redes públicas e privadas de ensino, sob um olhar dos docentes do Ensino Superior.

Por intermédio da participação dos professores entrevistados, foram constatadas divergências em meio à prática pedagógica da disciplina supracitada, nas respectivas redes de ensino. Contudo, notou-se que a visibilidade, o reconhecimento, o prestígio que a Educação Física tem dentro de uma instituição é advinda por meio da conduta do professor. Os entrevistados apontaram o uso da interdisciplinaridade como uma ferramenta por parte dos professores, para validação pedagógica da disciplina, fazendo com que a mesma não seja vista como uma disciplina secundária. Esse tipo de visão da Educação Física gerou um sentimento de desvalorização nos professores entrevistados, que percebem, no cotidiano escolar, a evidente hierarquização das disciplinas. Porém, a maior parte dos docentes entrevistados alegou que a disciplina é valorizada nas instituições em que atuam, considerando a participação deles nas ações e projetos pedagógicos realizados, no ambiente escolar, de forma efetiva.

Observou-se também a importância dos aspectos motivacionais para que a prática docente não venha a ser prejudicada e que isso requer uma identificação do próprio docente com a profissão. Não obstante, as condições de trabalho e valorização salarial influenciam nessa motivação. Muitos continuam a lecionar devido aos seus ideais e à participação dos alunos.

Todos os professores foram enfáticos quanto à formação permanente, tanto a informal quanto a formal, constatando-se que ela é relevante para que se tenha uma educação de qualidade. Porém, notou-se que nem sempre as instituições em que os docentes atuam dão esse espaço para que possam buscar por essa formação.

Os fatores socioeconômicos evidenciaram a diferença da realidade da escola pública e privada, com enfoques distintos. Nesse caso, a segunda volta-se para a preparação do aluno para prestar o vestibular, visando às universidades públicas, fato esse contraditório. Foi visto, por parte dos entrevistados, uma diferença mais nítida entre as duas redes - pública e privada - no aspecto da ação pedagógica e na parte correspondente à infraestrutura. Essa distinção também fica clara quanto ao público-alvo de ambas às instituições, já que as escolas públicas, invariavelmente, cumprem um papel predominantemente social, enquanto as particulares objetivam a transmissão de conhecimentos.

Nota-se a necessidade de elaboração de mais pesquisas referentes a essa área da Educação Física Escolar, pois a continuação de estudos na área poderá esclarecer melhor os aspectos citados e também acarretar o surgimento de outros novos. 


\section{REFERÊNCIAS BIBLIOGRÁFICAS}

AGEE, Jane. Developing qualitative research questions: a reflective process. International Journal of Qualitative Studies, v. 22, n. 4, p. 431-447, 2009. Disponível em:<http://dx.doi.org/10.1080/09518390902736512>. Acesso em: 15 set. 2013.

ALARCÃO, Isabel (Org.). Escola reflexiva e nova racionalidade. Porto Alegre: Artmed, 2001.

ANTUNES, Celso. 9 passos para uma escolar pública de excelente qualidade. Petrópolis - RJ: Vozes, 2013.

BARDIN, Laurence. Análise de conteúdo. São Paulo: Edições 70, 2011.

BOYLE, Spencer Earl et al. Physical activity among adolescents and barriers to delivering physical education in Cornwall and Lancashire. UK: a qualitative study of heads of PE and heads of schools. BMC Public Health, v. 8, n. 273, 2008. Disponível em: <http://www.biomedcentral.com/1471-2458/8/273>. Acesso em: 15 set. 2013.

BRACHT, Valter et al. Pesquisa em ação: educação física na escola. 3. ed. ljuí - SC: Editora Unijuí, 2007.

CASTELLANI FILHO, Lino. Educação física no Brasil: a história que não se conta. 15. ed. Campinas - SP. Papirus, 2008.

CRUZ, Marlon Messias Santana; PALMEIRA, Fernanda Caroline Cerqueira. Construção de identidade de gênero da educação física escolar. RevistaMotriz, Rio Claro, v. 15, n. 1, p. 116-131, 2009. Disponível em: <http://www.periodicos.rc.biblioteca.unesp.br/index.php/motriz/article/view/1470/2224>. Acesso em: 15 set. 2013.

DEMO, Pedro. Escola pública e escola particular. semelhanças de dois imbróglios educacionais. 2007. Disponível em: <http://repositorio.unb.br/bitstream/10482/8096/1/ARTIGO_EscolaPublicaEscolaParticular. pdf>. Acesso em: 11 jun. 2013.

FOLLE, Alexandra et al. Carreira no magistério público e nível de qualidade de vida no trabalho docente em Educação Física. Revista Motriz, Rio Claro, v. 14, n. 3, p. 210-221, jul/set. 2008. Disponível em:<http:// www.periodicos.rc.biblioteca.unesp.br/index.php/motriz/article/view/1396/1756>. Acesso em: 07 maio 2013.

FRANÇA, Caroline Fernandes et al. Análise sobre a motivação dos professores de educação física escolar e a profissionalização da docência. 2012. Disponível em: <https://www.fontouraeditora.com. br/periodico/vol-11/Vol11n1-2012/Vol11n1-2012-pag-71a80/Vol11n1-2012-pag-71a80.pdf>. Acesso em: 03 abr. 2014.

GONÇALVES, Hortência de Abreu. Manual de metodologia da pesquisa científica. São Paulo: Avercamp, 2005.

KANTERS, Michael A. et al. School sport participation under two school sport policies: comparisons by race/ethnicity, gender and socioeconomic status. 2012. Disponível em: <http://www.activelivingresearch. org/node/12620>. Acesso em: 11 jun. 2013.

LIBÂNEO, José Carlos. Didática. São Paulo: Cortez, 1990. 
MINAYO, Maria Cecília de Souza. 0 desafio do conhecimento: pesquisa qualitativa em saúde. 12. ed. São Paulo: Hucitec, 2010.

NASSER, Sérgio Daniel. Conflitos entre escola pública e escola privada e suas repercussões no cotidiano escolar do estudante da escola pública. 2011. Disponível em: <http://www.xiconlab.eventos.dype.com. br/resources/anais/3/1307103426_ARQUIVO_Congresso_Conflitosentreescolapublicaeescolaprivadaesuasrepercussoesnocotidianoescolardoestudantedaescolapublica.pdf $>$. Acesso em: 13 jun. 2013.

PIAGET, Jean. Psicologia e pedagogia: a resposta do grande psicólogo aos problemas do ensino. 9 ed. Rio de Janeiro: Forense Universitária, 2008.

PIMENTA, Selma Garrido et al. 0 papel da escola pública no Brasil contemporâneo. 1. ed. São Paulo: Edições Loyola, 2013.

RANGEL, I. C. A. et al. Educação física escolar e multiculturalismo: possibilidades pedagógicas. Motriz, v. 14, n.2, 2008.

SANTOS, Izequias Estevam dos. Manual de métodos e técnicas de pesquisa científica. Niterói - RJ: Impetus, 2011.

SILVA, Luciene Ferreira. Educação, educação física e sociedade: implicações na atualidade. Revista Motriz, Rio Claro, v. 14, n. 4, p. 408-417, out/dez. 2008. Disponível em:<http://www.periodicos.rc.biblioteca. unesp.br/index.php/motriz/article/view/2138>. Acesso em: 06 maio 2013.

SILVA, Rudney ; MACIEL, Paola Belezza. Características da Educação Física do Ensino Médio noturno. Revista Motriz, Rio Claro, v.15, n.2, p. 247-256, abr./jun. 2009. Disponível em: <http://seer.ufrgs.br/index. php/Movimento/article/view/2495/1139>. Acesso em: 03 abr. 2014.

SOUZA JUNIOR, Marcílio Barbosa Mendonça et al. A análise de conteúdo como forma de tratamento dos dados numa pesquisa qualitativa em educação física escolar. Revista Movimento, Porto Alegre, $\mathrm{v}$. 16, n. 3, p. 31-49, jul/set. 2010. Disponível em: <http://seer.ufrgs.br/Movimento/article/view/11546>. Acesso em: 20 set. 2013. 